\title{
How are you? Do people with inflammatory bowel disease experience response shift on this question?
}

Nancy E Mayo ${ }^{1 *}$, Susan C Scott ${ }^{2}$, Charles N Bernstein ${ }^{3}$ and Lisa M Lix

\begin{abstract}
Background: As individuals experience changes in their health, they may alter the way they evaluate health and quality of life. The purpose of this study is to estimate the extent to which individuals with IBD change their rating of health over time because of response shift (RS).

Methods: This is a reanalysis of a population-based longitudinal study of IBD in Manitoba, Canada $(n=388)$. RS was examined using trajectories of the difference between observed and predicted health. Logistic regression and dual trajectories were used to identify predictors of RS.

Results: Disease activity, vitality, pain, somatization, and physical and social function explained $51 \%$ of the variation in general health over two years with no evidence of RS in $82 \%$ of the sample. Negative RS was found for $8 \%$, who initially rated health better than predicted; positive RS was found for $6 \%$. The positive RS group was younger and had better baseline scores on measures of general health, hostility, pain, mental health and social and role function; less pain and better social function scores at baseline were predictors of negative RS.

Conclusions: In conclusion, the majority of people with IBD did not demonstrate a RS indicating that the health rating over time was stable in relation to that predicted by known time varying clinical variables. This adds to the evidence that the single question on self-rated health is useful for monitoring individuals over time.
\end{abstract}

Keywords: Response shift, Measurement of change, Quality of life, Inflammatory bowel disease, Longitudinal

\section{Introduction}

Health-related quality of life (HRQL) is a broad concept that encompasses multiple domains, including physical, psychological, social, and emotional health, as well as general or global perceptions of health [1,2]. Longitudinal studies about HRQL and other patient-reported outcomes rest on the assumption that the respondent's interpretation of a construct remains constant over time. Increasingly, HRQL measures are being used in clinical trials to evaluate the efficacy of new treatments or interventions, population-based surveys to describe population health, and chronic disease cohort studies to understand the impact of health challenges and treatment over the disease course. In longitudinal studies, a question of

\footnotetext{
* Correspondence: nancy.mayo@mcgill.ca

'Division of Clinical Epidemiology, Ross Pavilion R4. 29, Royal Victoria Hospital Site, McGill University Health Center, Montreal, QC H3A 1A1, Canada Full list of author information is available at the end of the article
}

primary interest is: "Is there a significant improvement or deterioration in global HRQL and its domains?"

As individuals experience changes in their health, they may change the way that they evaluate their health and quality of life. Response shift (RS) is defined as a change in an individual's internal standards (recalibration), values (reprioritization), or conceptualizations of health (reconceptualization) [3]. It is theorized that RS occurs when individuals experience a significant health event (i.e., catalyst), such as a stroke, cancer treatment, or chronic disease diagnosis [4]. When RS is present in HRQL, conventional statistical analyses may not reveal any evidence of an observed change even when a true change exists. Moreover, RS may not affect all HRQL domains or all samples, sub-samples, or individuals equally, which can complicate longitudinal data analysis.

Methods to detect RS include: (a) Design-based methods that collect supplementary data to estimate the 
magnitude of RS, (b) Interview or focus group methods that collect qualitative information about individuals' experiences of RS, (c) Preference-based methods that collect comparative data about changes in the rank-order of domains, and (d) Model-based methods based on measurement error, multivariate, and longitudinal statistical models [5].

The most common design based method is the 'then' test [6]. Individuals evaluate HRQL at the baseline occasion and then again at the post-test (or follow-up) measurement occasion. At the post-test, individuals are also asked to re-evaluate their HRQL at the pretest (baseline) assessment occasion. The difference between the original pretest score and the retrospective pre-test score estimates the magnitude of RS. The 'then' test has several limitations: it must be built in at the design stage, it can only be used to estimate recalibration, it is sensitive to recall bias and social acceptability bias, and it is problematic to use when there are multiple measurement occasions $[7,8]$. The other design based methods have similar challenges with respect to data collection and respondent burden.

Model-based methods include: (a) structural equation models (SEM) [9-13]; (b) random-effects models, (c) relative important measures, and (d) classification models. Of these methods, random-effects models are more easily applicable in the case of multiple time points. We previously [14] described a subject-specific model-based method of testing for RS in data collected at multiple occasions. This is a useful method when the pattern of change over time may be influenced by the course of progression of a health condition. The method focuses on an analysis of the pattern of residuals (the difference between predicted and observed HRQL scores) over time, classifying people into discrete RS groups. This method has been used in an inception cohort of individuals with stroke [14] and in a large volunteer study of individuals with prevalent multiple sclerosis (MS) [15]. These two samples yielded, not surprisingly, different prevalences of response shift: $33 \%$ for stroke and $1 \%$ for MS. The high rates found in the stroke cohort are in keeping with the concept of RS resulting from a catalyst; incident stroke is a strong catalyst with a definitive onset. MS, which shares commonalities with other chronic diseases such as inflammatory bowel disease (IBD) and rheumatoid arthritis, develops over a longer time period and severity fluctuates. However, for the MS sample studied for RS, the timing of measurements was determined by the individual and not a study protocol. Thus, individuals may have chosen to report only when they were feeling well, and the picture of disease impact over time may have been minimized.

RS is an important consideration when evaluating changes in disease outcomes because it can result in an overestimating of problems or benefits in some individuals, and an underestimation in others. In a research context, these effects could cancel, yielding a conclusion of no change $[16,17]$. IBD is a chronic inflammatory disease with two distinct entities: Crohn's disease and ulcerative colitis. However, regardless of the type of disease, over its course, individuals will experience changes in the intensity and severity of their symptoms. When there is increased inflammation, the disease is considered to be in an active stage and the individual will experience a flare-up of the condition, which may severely affect participation in work and social functions $[18,19]$. Symptoms include pain, fatigue and diarrhea; IBD is also associated with mastery, distress and lower psychological well-being [20,21]. When the degree of inflammation is low, the individual usually has mild symptoms or is symptom-free. Medical and surgical management has varying success, with up to half of individuals with IBD experiencing relapses every year. All of these aspects take a toll on health and quality of life of persons with IBD $[20,22,23]$.

In order to accurately interpret IBD impact over time, from both the perspective of an individual and for group comparisons, it is important to have methods to identify RS. The area of IBD is understudied for this phenomenon.

The purpose of this study is to estimate the extent to which RS occurs among individuals with IBD, and to identify predictors of RS.

\section{Methods}

\section{Data}

Data for this analysis is from the Manitoba IBD Cohort Study, a prospective longitudinal cohort study that is investigating the determinants of disease outcomes. Initiated in 2002, the Cohort Study includes persons from a population-based registry, which was established in 1995 at the University of Manitoba. The formation of this cohort is described in previous publications [20,21]. The present study is a reanalysis of the data, which consists of 388 respondents, 18 years of age or older and diagnosed within seven years prior to enrollment (mean 4.3 standard deviation 2.1), with data collected by mail questionnaire at 5 measurement occasions between study entry and 24-months. During this period, 34 respondents $(8.8 \%)$ dropped out.

\section{Measures}

Respondents in the Manitoba IBD Cohort Study provided demographic information and information on a wide spectrum of health outcomes related to disease activity, physical and psychological symptoms, physical, role and social function, perceived health, and social support. Physical symptoms cover pain, fatigue and vitality, as well as those relating to the gastrointestinal system. Psychological symptoms include anxiety, mood, and somatic and systemic symptoms. 
The outcome for this study is the single-item from the SF-36 General Health Perception (GHP) subscale: "In general would you say your health is", with response options Excellent, Very Good, Good, Fair, Poor (EVGGFP). The other sub-scales of the SF-36 assess physical and social function, pain, vitality, mental health, and physical and emotional role impact, and were used as potential predictors of EVGGFP. All subscales are scored from 0 to 100, with higher values indicating better health. Some questions refer to the past four months, others, a typical day. The SF-36 has been widely validated as a measure of perceived health status [24,25]. Disease activity was assessed using the Manitoba IBD Index [26], a single-item index for symptom persistence based on the previous six-month period, shown to have good validity. IBD-specific predictors were selected from the Inflammatory Bowel Disease Questionnaire (IBDQ) [27]: gastrointestinal symptoms, systemic problems (fatigue, energy, feeling unwell, sleep, weight), emotional dysfunction, and social difficulties during the last two weeks. The IBDQ is a commonly used and extensively validated measure of HRQL in IBD [28].

Negative psychological functioning was assessed using the Cohen Perceived Stress Scale (CPSS), which asks about feelings and thoughts during the last month. It is a validated tool for measuring the role of stress in disease $[29,30]$.

The Brief Symptom Inventory (BSI) measures depressive symptoms from the past seven days in nine dimensions: somatization, obsession-compulsion, interpersonal sensitivity, depression, anxiety, hostility, phobic anxiety, paranoid ideation, and psychoticism [31].

The Multidimensional Scale of Perceived Social Support (MSPSS) [32], with 12 items, assesses the degree of support from family and friends, presumably currently.

\section{Statistical analyses}

The statistical methods have been described previously $[14,15]$ and Figure 1 outlines the steps. The method starts with the creation of the random-effects model using, as predictors of outcome (EVGFP), those variables measured over time: symptoms, functioning, perceived stress, and social support. All assumptions underlying linear models are tested and modifications made to ensure linearity and/ or monotonicity. A key feature is that time is not in the model nor are any variables that interact with time, as time is considered part of the catalyst for RS. Assessments missing either the outcome or more than half of the predictor variables included in the final model were dropped. Remaining missing items were categorized with missing levels in the predictive model. Model fit was evaluated using Akaike Information Criterion (AIC) and Bayesian Information Criteria (BIC). A pseudo-R [2] was calculated to estimate the proportion of total variation in EVGGFP explained by the final model [33].
The detection of RS is based on the patterns of residuals over time, which are the differences between predicted EVGGFP and the observed value for each respondent at each time period. These residual values were centered by subtracting each respondent's mean residual from each time-specific residual to focus on change over time rather than on each respondent's deviation from expected. Persons with fewer than three residuals were excluded from further analysis.

Nagin's group-based trajectory method [34] was used to identify respondents considered likely to have experienced a RS based on the patterns of residuals over time. Large fluctuations in a respondent's observed and predicted health over time suggest that a RS has occurred, while a pattern of consistent residuals over time (though not necessarily close to predicted) suggests no response shift. GBTA is a form of latent class analysis for continuous outcomes based on the assumption that the population is a mixture of distinct groups defined by common change over time, while recognizing uncertainty in group membership. RS trajectories are qualitatively classified based on their shape and direction, reflecting the change in the centered residuals.

Posterior probabilities, representing a respondent's likelihood of belonging to each of the trajectory groups, are provided for each respondent for each trajectory. They are used to calculate theoretical and assigned proportions. The theoretical proportion is an expected value calculated as the sum of posterior probabilities for that trajectory group over all respondents; the assigned proportion is calculated from each respondent's highest posterior probability. Similarity between the theoretical and assigned probabilities is considered to indicate good model fit, as are respondents having a high posterior probability for a single group (measured using means of the group with the highest posterior probability). Other indicators of model fit are based on the AIC and BIC statistics, where values closer to zero indicate better fit. Two BIC statistics are produced, one based on the number of respondents, the other on the number of observations, with the correct but incalculable BIC lying between the two. Coherence with theory and all fit indices are considered in determining the number of trajectory groups and the number of parameters per trajectory (intercept, linear, quadratic, etc.).

Four response shift patterns were hypothesized based on other work [14]: none, positive, negative, or fluctuating. No response shift is likely when the centered residuals form a flat trajectory at 0: the difference between predicted and observed is consistent across time. Positive RS is deemed present when the magnitude of the residual increases over time in a direction of a more positive rating. This includes respondents who start with health ratings worse than predicted but who increase 


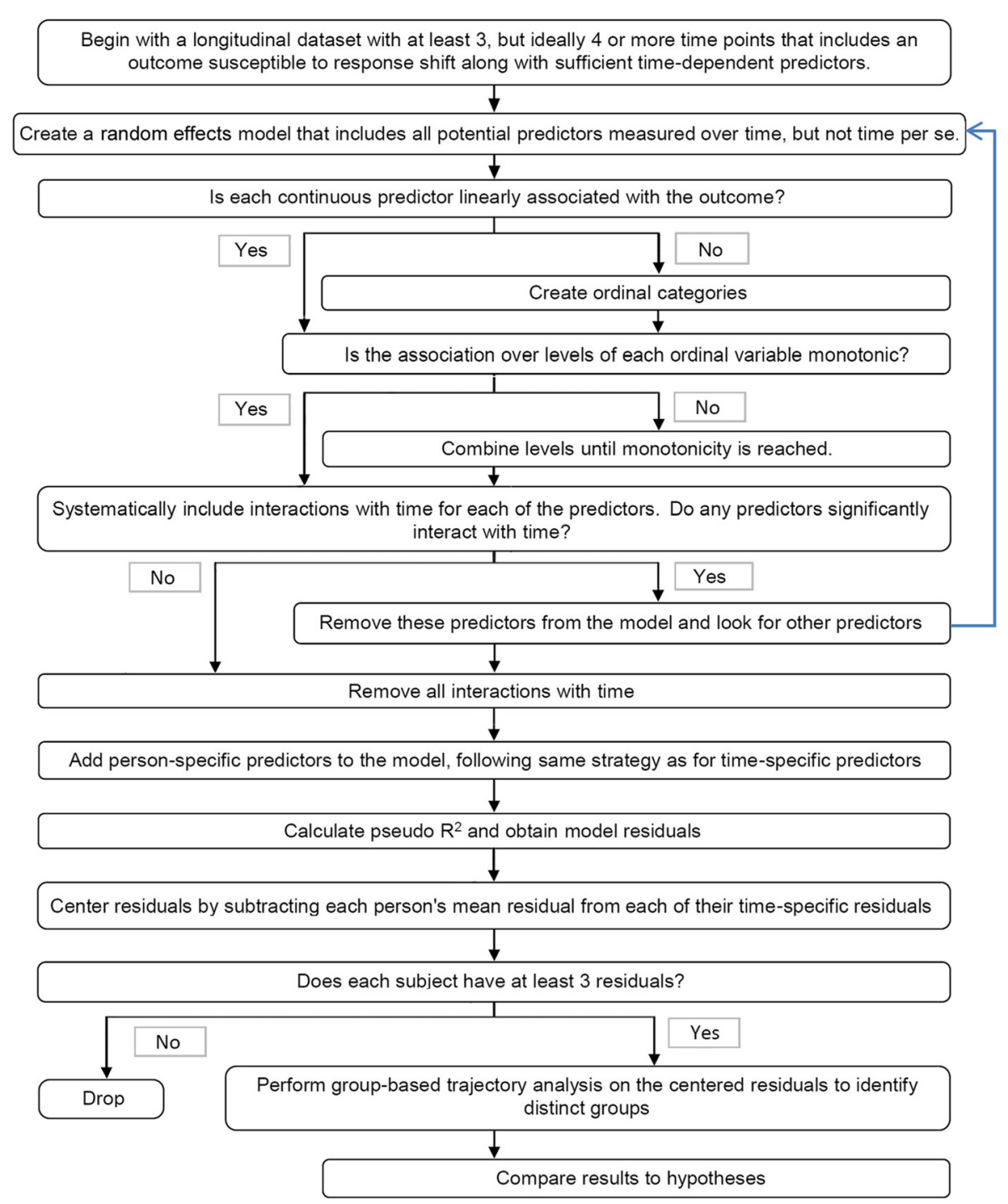

Figure 1 Flowchart of methods,

their rating over time to be better than predicted, as well as respondents who may begin better than expected but, over time, increase to a rating that is even more positive than expected. Negative RS is deemed present when respondents rate their health better than (or closer to) expected early on, but whose ratings decrease over time compared to expected.

To answer the question as to whether response shift depends on perceived health, we modeled the trajectories of RS conditional on the trajectories of EVGGFP using dual trajectory analysis [34].

To answer the question as to who is likely to experience a RS, we created two logistic regression models one to identify predictors of positive RS and one to predict negative RS. Although trajectory analysis is a probabilistic method, in that respondents receive a posterior probability of being in each trajectory group, respondents can be assigned deterministically to a specific group based on their highest probability. Odds ratios and 95\% confidence intervals (CI) were estimated for each variable measured at baseline. With five levels and a reasonably normal distribution, EVGGFP can be modeled as continuous with little repercussion $[14,15,35]$.

\section{Ethical considerations}

Ethics approval for the Cohort Study was obtained from the University of Manitoba Health Research Ethics Board.

\section{Results}

\section{Description of the cohort}

Table 1 gives the characteristics of the sample; the mean age was 40 years, $60 \%$ were women, and there were 
Table 1 Characteristics of IBD cohort study participants ( $n=388$ )

\begin{tabular}{|c|c|c|c|}
\hline Characteristic & $\mathrm{N}$ missing & $\begin{array}{l}N \text { or } \\
\text { Mean (SD) }\end{array}$ & Proportion \\
\hline Sex: (men/women) & 0 & $157 / 231$ & $40 \% / 60 \%$ \\
\hline Age at baseline: Mean (SD) & 5 & $40.4(14.5)$ & \\
\hline$<25 / 25-64 / \geq 65$ & 5 & $57 / 305 / 21$ & $15 \% / 80 \% / 5 \%$ \\
\hline $\begin{array}{l}\text { Age at diagnosis: } \\
\text { Mean (SD) }\end{array}$ & 9 & $36.0(14.6)$ & \\
\hline Diagnosis & 0 & & \\
\hline Crohn's & & 187 & $48 \%$ \\
\hline Ulcerative colitis [1] & & 187 & $48 \%$ \\
\hline Indeterminate IBD & & 14 & $4 \%$ \\
\hline $\begin{array}{l}\text { Education: High School } \\
\text { or less/Trade School } \\
\text { or Diploma/University }\end{array}$ & 35 & 137/119/97 & $39 \% / 34 \% / 27 \%$ \\
\hline Employment: & 6 & & \\
\hline Working full time & & 204 & $53 \%$ \\
\hline In school & & 95 & $25 \%$ \\
\hline Working part-time & & 34 & $9 \%$ \\
\hline Homemaker & & 26 & $7 \%$ \\
\hline Retired & & 20 & $5 \%$ \\
\hline Disabled & & 3 & $<1 \%$ \\
\hline Worked in last year & 7 & 313 & $82 \%$ \\
\hline $\begin{array}{l}\text { Missed work in last } \\
6 \text { months due to IBD }\end{array}$ & 37 & 116 & $33 \%$ \\
\hline
\end{tabular}

[1] 18 of the 187 are indeterminate collitis.

similar numbers of respondents with Crohn's disease and ulcerative colitis. Over half of the sample was working full time at baseline but 33\% of respondents had missed work in the previous 6 months because of IBD.

\section{Ratings of health}

Table 2 presents the proportion of respondents who were concordant on rating of health (EVGGFP) at study entry and 2 years later. Half reported the same level of health at study entry and at two years follow-up, while $27 \%$ reported better health, and 23\% deterioration. Of the 90 respondents who rated their health as Very Good at study entry, $10(11.1 \%)$ rated their health higher at the 2-year follow-up, while 32 (35.6\%) rated their health lower.

\section{Time-dependent measures}

Table 3 presents the distribution of those variables measured at each assessment: symptoms, functioning, health perception, and social support. For the SF-36 subscales, Canadian population norms are presented. For most of the subscales, the IBD cohort members had considerably lower values.
Table 2 SF-36 General health question (EVGGFP) at study entry and 2 years later among $289(74 \%)$ with ratings at both measurement occasions

\begin{tabular}{|c|c|c|c|}
\hline \multirow{2}{*}{$\begin{array}{l}\text { Rating at } \\
\text { Cohort entry } \\
\text { (n) }\end{array}$} & \multicolumn{3}{|l|}{ Rating at 2 years } \\
\hline & $\begin{array}{l}\text { Concordant } \\
(n=144,49.8 \%)\end{array}$ & $\begin{array}{l}\text { Increased } \\
(n=78,27.0 \%)\end{array}$ & $\begin{array}{l}\text { Decreased } \\
(n=67,23.2 \%)\end{array}$ \\
\hline Excellent (12) & $4(33.3 \%)$ & - & $8(66.7 \%)$ \\
\hline Very good (90) & $48(53.3 \%)$ & $10(11.1 \%)$ & $32(35.6 \%)$ \\
\hline Good (116) & $64(55.2 \%)$ & $28(24.1 \%)$ & $24(20.7 \%)$ \\
\hline Fair (52) & $24(46.2 \%)$ & $25(48.1 \%)$ & $3(5.8 \%)$ \\
\hline Poor (19) & $4(21.1 \%)$ & 15 (78.9\%) & - \\
\hline
\end{tabular}

Proportions are row percents among persons at each of the five levels of outcome.

\section{Predictive model of health}

The model used to predict health perception is presented in Table 4. Of the 388 respondents in the cohort, three had no measurement occasions with the EVGGFP question answered and were removed from further analysis, as were three assessments where data were missing. The final model was based on 1691 records among 385 respondents. Most respondents $(87 \%$ of the 388) had the EVGGFP outcome available for at least four measurement occasions. The predictive model explained $51.3 \%$ of the variation in EVGGFP (AIC $=3123.8$, $\mathrm{BIC}=3206.8$ for model with predictors compared to $\mathrm{AIC}=3883.1, \quad \mathrm{BIC}=3894.9$ for the null model). Symptom frequency and duration (both over the past 6 months and over the past 2 weeks) were significant predictors of EVGGFP and had initially been included, but as their impacts changed over time (and as such are part of the RS) these predictors were dropped from the model and others, including a binary indicator of active disease, were allowed to enter.

\section{Group-based trajectory model of residuals}

The group-based trajectory model was based on 359 of 385 respondents who had at least three residuals. We first considered a 6-trajectory group model which statistically fit the data well (AIC -902.33, BIC $(n=1653$ based on records) -991.60 , BIC $(\mathrm{n}=359$ based on persons) -966.40); however, two of the trajectories (representing less than $10 \%$ of the sample) showed no consistent pattern and variation was within the precision of the measurement scale (1 unit). Table 5 shows the fit parameters of the final, four-trajectory group model (AIC-963.32, BIC $(\mathrm{n}=1653)-1017.42$, BIC $(\mathrm{n}=$ 359) -1002.15) which also showed very good fit: all mean posterior probabilities were greater than 0.90 , and theoretical and assigned proportions were almost identical. Figure 2 shows the four trajectories. Because of the centering of the residuals prior to modeling, a flat line at zero does not necessarily indicate agreement with the predicted score, but rather consistency over 
Table 3 Disease activity, symptoms, functioning and social support at study entry and at one- and two-year follow-ups

\begin{tabular}{|c|c|c|c|c|c|c|}
\hline \multirow{2}{*}{$\begin{array}{l}\text { Predictor } \\
\text { [norm when available] }\end{array}$} & \multicolumn{2}{|c|}{ Study entry } & \multicolumn{2}{|c|}{ Year 1 follow-up } & \multicolumn{2}{|c|}{ Year 2 follow-up } \\
\hline & $\mathrm{n}$ & Mean (SD) & $\mathrm{n}$ & Mean (SD) & $\mathrm{n}$ & Mean (SD) \\
\hline \multicolumn{7}{|c|}{ SF-36 subscales: scored 0-100, higher scores correspond to better HRQL } \\
\hline General health perception [77] & 284 & $54.9(21.3)$ & 357 & $53.0(21.4)$ & 342 & $56.9(22.3)$ \\
\hline Physical function [86] & 335 & $81.0(21.5)$ & 354 & $82.5(21.8)$ & 345 & $83.2(22.0)$ \\
\hline Role physical [82] & 379 & $69.1(29.0)$ & 357 & $75.2(26.7)$ & 346 & $77.1(25.1)$ \\
\hline Bodily pain [76] & 351 & $58.3(23.8)$ & 360 & $61.8(21.7)$ & 348 & $62.7(22.1)$ \\
\hline Vitality [66] & 380 & $49.5(20.8)$ & 359 & $51.8(21.8)$ & 345 & $51.5(22.8)$ \\
\hline Social function [86] & 381 & $67.4(27.9)$ & 358 & $79.5(24.8)$ & 347 & $79.2(23.3)$ \\
\hline Role emotional [84] & 379 & $78.7(23.1)$ & 360 & $83.0(22.2)$ & 347 & $83.3(21.2)$ \\
\hline Mental health [78] & 379 & $67.6(17.3)$ & 360 & $71.5(17.3)$ & 345 & $71.7(18.4)$ \\
\hline \multicolumn{7}{|c|}{ IBDQ subscales: scored 0 to 7 , higher scores correspond to better HRQL } \\
\hline Bowel symptoms & 364 & $5.3(1.1)$ & 350 & $5.4(1.1)$ & 343 & $5.5(1.1)$ \\
\hline Emotional health & 338 & $5.2(1.1)$ & 354 & $5.4(1.1)$ & 344 & $5.5(1.0)$ \\
\hline Social function & 346 & $5.9(1.3)$ & 336 & $6.1(1.3)$ & 336 & $6.2(1.1)$ \\
\hline Systemic symptoms & 365 & $4.4(1.3)$ & 352 & $4.6(1.3)$ & 344 & $4.7(1.3)$ \\
\hline \multicolumn{7}{|c|}{ Brief symptom inventory: scaled 0 to 100 , higher scores indicate worse symptoms } \\
\hline Global & 381 & $13.7(12.0)$ & 358 & $12.9(12.1)$ & 351 & $12.2(10.8)$ \\
\hline Somatization & 379 & $17.2(15.0)$ & 358 & $16.2(15.6)$ & 351 & $14.8(15.1)$ \\
\hline Somatization excluding nausea & 379 & $15.9(14.9)$ & 358 & $14.5(15.2)$ & 351 & $13.6(14.9)$ \\
\hline Obsessive compulsive & 381 & $21.2(18.1)$ & 358 & $21.2(18.9)$ & 351 & $20.0(16.4)$ \\
\hline Sensitivity & 381 & $14.7(17.6)$ & 358 & $13.4(16.8)$ & 352 & $13.1(16.0)$ \\
\hline Depression & 381 & $15.6(18.3)$ & 358 & $12.5(16.5)$ & 352 & $12.9(15.0)$ \\
\hline Anxiety & 380 & $13.3(14.6)$ & 358 & $12.8(14.8)$ & 352 & $11.3(13.0)$ \\
\hline Hostility & 381 & $13.0(13.9)$ & 358 & $11.8(12.5)$ & 351 & $11.1(11.8)$ \\
\hline Phobic & 379 & $5.1(10.6)$ & 358 & $5.1(12.1)$ & 351 & $4.0(9.0)$ \\
\hline Paranoid & 380 & $9.4(12.8)$ & 358 & $9.6(13.8)$ & 352 & $9.9(13.9)$ \\
\hline Psychoticism & 381 & $7.0(11.2)$ & 358 & $7.1(11.0)$ & 351 & $7.6(11.3)$ \\
\hline \multicolumn{7}{|c|}{ MSPSS social support: higher scores correspond to greater support. Total is scored 12-84 } \\
\hline Total & 341 & $66.2(14.1$ & 358 & $65.4(16.1)$ & 349 & $65.7(16.5)$ \\
\hline Significant other (1-7) & 346 & $5.8(1.5)$ & 358 & $5.8(1.6)$ & 349 & $5.8(1.6)$ \\
\hline Family (1-7) & 374 & $5.6(1.4)$ & 359 & $5.5(1.5)$ & 351 & $5.5(1.5)$ \\
\hline Friends $(1-7)$ & 375 & $5.2(1.5)$ & 359 & $5.1(1.5)$ & 351 & $5.1(1.6)$ \\
\hline \multicolumn{7}{|c|}{ CPSS Stress scale: scored 0-56, higher scores correspond to greater perceived stress } \\
\hline CPSS total & 371 & $22.4(8.2)$ & 356 & $21.4(8.5)$ & 344 & $20.9(8.7)$ \\
\hline
\end{tabular}

time in the difference between the observed and expected scores. The majority of the sample (82\%) was part of the flat trajectory at 0 , indicating no RS. A small proportion (6\%) was part of a trajectory with centered residuals that dropped over the first six months, generally respondents who started with health ratings worse than predicted but that increased with respect to predicted; this group is labeled as showing positive RS. A further $8 \%$ started with scores generally better than predicted, but decreased their health rating compared to predicted over the next six months, labeled negative RS. Another 3\% started better than expected but rated themselves considerably worse at 6 months, but with a return thereafter; this group is labeled as having a rebound response-shift pattern.

\section{Observed versus predicted health}

A graph of observed and predicted EVGGFP by trajectory group is presented in Figure 3. All trajectory groups follow a similar predicted course over time. The trajectories of 
Table 4 Best predictive model of EVGGFP over time

\begin{tabular}{llll}
\hline Variable & Scale & Beta (SE) & p \\
\hline Active disease & Y/N & $0.242(0.039)$ & $<.0001$ \\
IBDQ systemic & $0-6$ & $0.070(0.022)$ & 0.0014 \\
SF-36 vitality & $100-0$ & $0.010(0.001)$ & $<.0001$ \\
SF-36 pain & $100-0$ & $0.006(0.001)$ & $<.0001$ \\
BSI somatization* & $0-83.33$ & $0.005(0.002)$ & 0.0021 \\
BSI psychoticism & $(30-85)$ vs (0-25) & $0.207(0.070)$ & 0.0030 \\
SF-36 physical function & $100-0$ & $0.008(0.001)$ & $<.0001$ \\
IBDQ social function & $6.5 \vee 7$ & $0.047(0.043)$ & 0.2702 \\
& $5.5-6.5 \vee 7$ & $0.086(0.049)$ & 0.0792 \\
& $<4.5 \vee 7$ & $0.133(0.061)$ & 0.0295
\end{tabular}

Predictors modeled with lower as the better score and higher as worse. Gender was also included, as it explained variance, but only time-dependent variables contribute to the residuals that are modeled. BSI $=$ Brief Symptom Inventory; IBDQ = Inflammatory Bowel Disease Questionnaire. *excluding nausea/upset stomach.

observed and predicted health ratings among the 82\% classified as not having experienced RS are essentially identical (Figure 3a). However, among the $8 \%$ with negative RS, it can be seen that, while health was rated higher at the first interview, ratings reached a plateau similar to predicted by 6 months (Figure 3b). Among the 6\% classified as having positive RS, while they began poorly compared to predicted, by 6 months they reached an average rating slightly better than expected (Figure 3c). The rebound group (3\%) rated health worse than predicted by 6 months, but higher than predicted at 2 years (Figure 3d).

\section{Dual trajectory analysis}

Figure 4 shows the trajectories of the health rating over time (EVGGFP). There were four flat groups, $24 \%$ at VG, 50\% near G, 18\% near $\mathrm{F}$ and $4 \%$ between $\mathrm{F}$ and $\mathrm{P}$, and two changing groups, one (3\%) with improving health rating and one with predominantly decreasing health rating $(2 \%)$.

Table 5 Trajectory groups of RS categories

\begin{tabular}{|c|c|c|c|c|}
\hline & $\begin{array}{l}\text { No RS } \\
\text { detected }\end{array}$ & Negative RS & Positive RS & Rebounded \\
\hline Theoretical\% & 82.1 & 8.3 & 6.4 & 3.3 \\
\hline $\begin{array}{l}\mathrm{N}(\%) \text { based on } \\
\text { assignment }\end{array}$ & 294 (81.9\%) & $31(8.6 \%)$ & $23(6.4 \%)$ & $11(3.1 \%)$ \\
\hline \multicolumn{5}{|c|}{ Range of centered residuals } \\
\hline Mean (SD) & $0.89(0.34)$ & $2.00(0.45)$ & $2.22(0.59)$ & $2.03(0.50)$ \\
\hline Min-Max & $0.07-1.58$ & $1.43-3.11$ & $1.59-3.67$ & $1.35-3.02$ \\
\hline \multicolumn{5}{|c|}{$\begin{array}{l}\text { Posterior probability of } \\
\text { belonging to RS group } \\
\text { (>0.7 considered good fit) }\end{array}$} \\
\hline Mean (SD) & $0.99(0.04)$ & $0.92(0.16)$ & $0.95(0.11)$ & $0.93(0.15)$ \\
\hline
\end{tabular}

Modelled on 1,653 observations among 359 subjects with at least 3 outcomes at interviews with at least half the predictors.

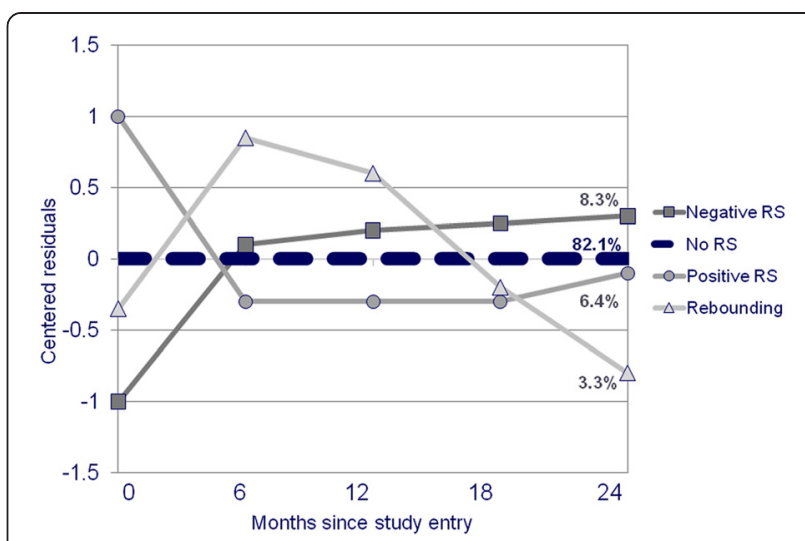

Figure 2 Four-trajectory model of response shift.

Results from the dual trajectory analysis of EVGGFP modeled conditionally on RS group indicate that only four trajectories of health could be modeled jointly, with some small redistribution of people into trajectories. These are: three flat groups, one between poor and fair (20\%) and two others at good (51\%) and at VG (24\%), and the remaining $5 \%$ of the sample with improving health ratings from $\mathrm{F}$ to $\mathrm{VG}$ over the two year period.

Figure 5 shows the distribution of health rating trajectories over RS groups, first over the full sample to serve as an expected distribution without considering RS and then for each RS group separately. Approximately 24\% rated their health as stable at VG and this distribution was similar for all RS groups except for the positive RS group. Overall, only a small proportion of respondents $(5 \%)$ rated their health as improving but $62 \%$ of RS positive and $40 \%$ of RS rebound did so, recognizing that both these groups are small ( $6 \%$ and $4 \%$ of all groups, respectively).

\section{Predictors of RS}

Predictors of RS are presented in Table 6. Univariate comparisons of the 23 respondents assigned to the positive RS group with the 294 in the RS null group indicate that those with positive RS are more likely to be younger (on average, diagnosed at 30 compared to 38 , for an odds ratio of 0.96 associated with each additional year of age), to have more hostility symptoms and to report worse scores for pain, mental health, social and role physical functioning and general health perception at baseline. As higher scores on the SF-36 signify better HRQL, the risk of positive RS was lower when baseline scores were higher. Thus, lower baseline scores on the GH subscale were more likely among respondents with positive RS. Worse baseline pain and social function scores were also found to be associated with the presence of negative as well as positive RS. Gender, vitality, physical function, and measures of personality and coping type were not found to have an association with RS. 


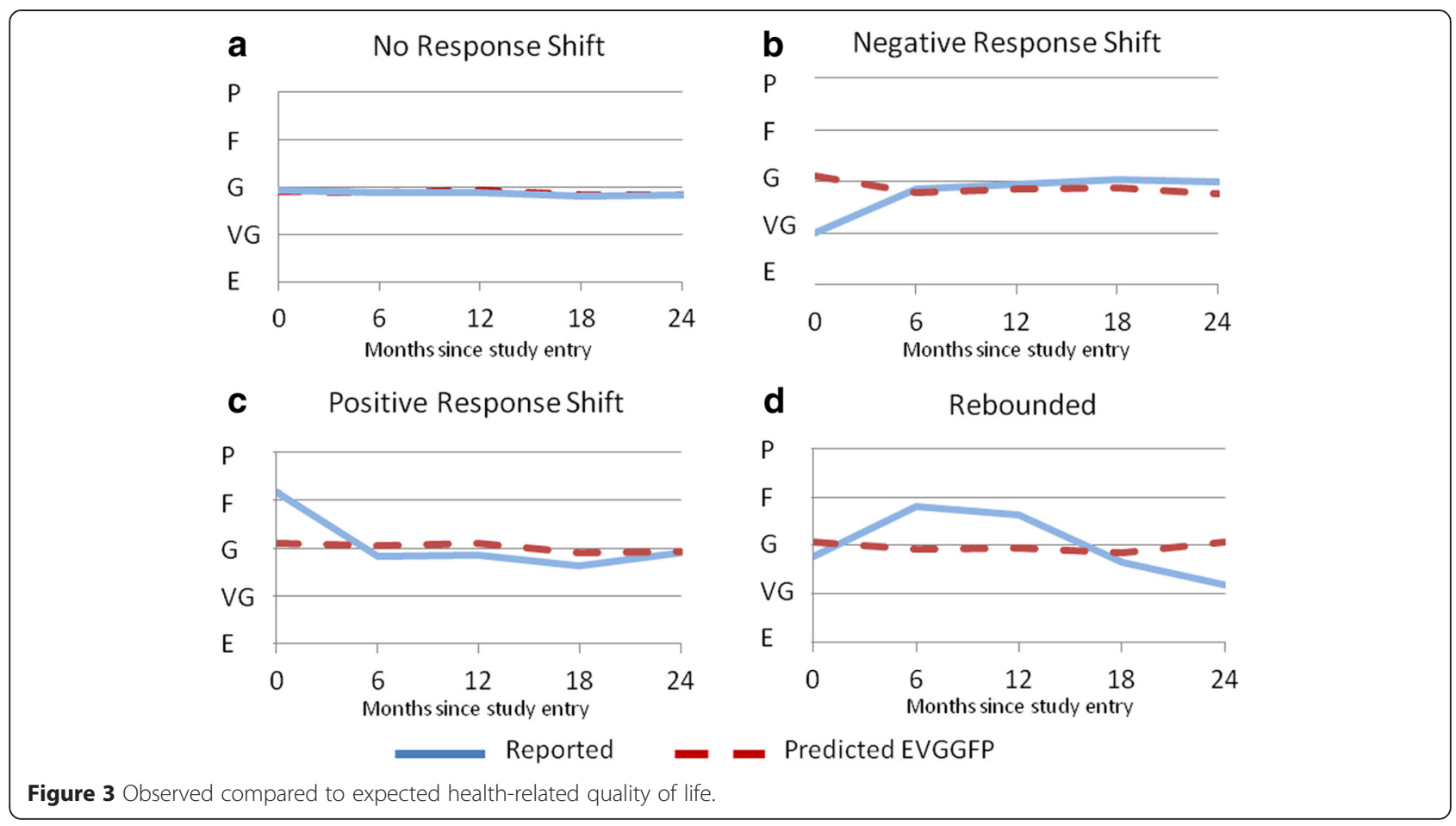

\section{Discussion}

This study found no evidence of RS in $82 \%$ of the cohort on one of the most frequently asked questions in health. This suggests that this is a good question to ask over time in this population.

Positive RS was experienced by $6 \%$ of the IBD sample and negative RS by $8 \%$ over a two-year period. These RS rates are lower than were found over one year in a sample of incident stroke (14\% positive and $15 \%$ negative), but higher than were found in a volunteer study of prevalent MS. While the diagnosis of a chronic disease such as IBD would be expected to be a sufficient catalyst to initiate a RS, it is not surprising that stroke, an event with a very precise onset that can produce serious health consequences in the blink of an eye, would be a stronger catalyst, resulting in more RS, even over a shorter time period. Also, while this IBD cohort was established within seven years of diagnosis (mean years since diagnosis $=4, \mathrm{SD}=2$ ), it may be that $\mathrm{RS}$ occurs early and was missed in some respondents. Both the positive and negative RS found in this study occurred by 6 months of follow-up. We previously detected almost no RS in a

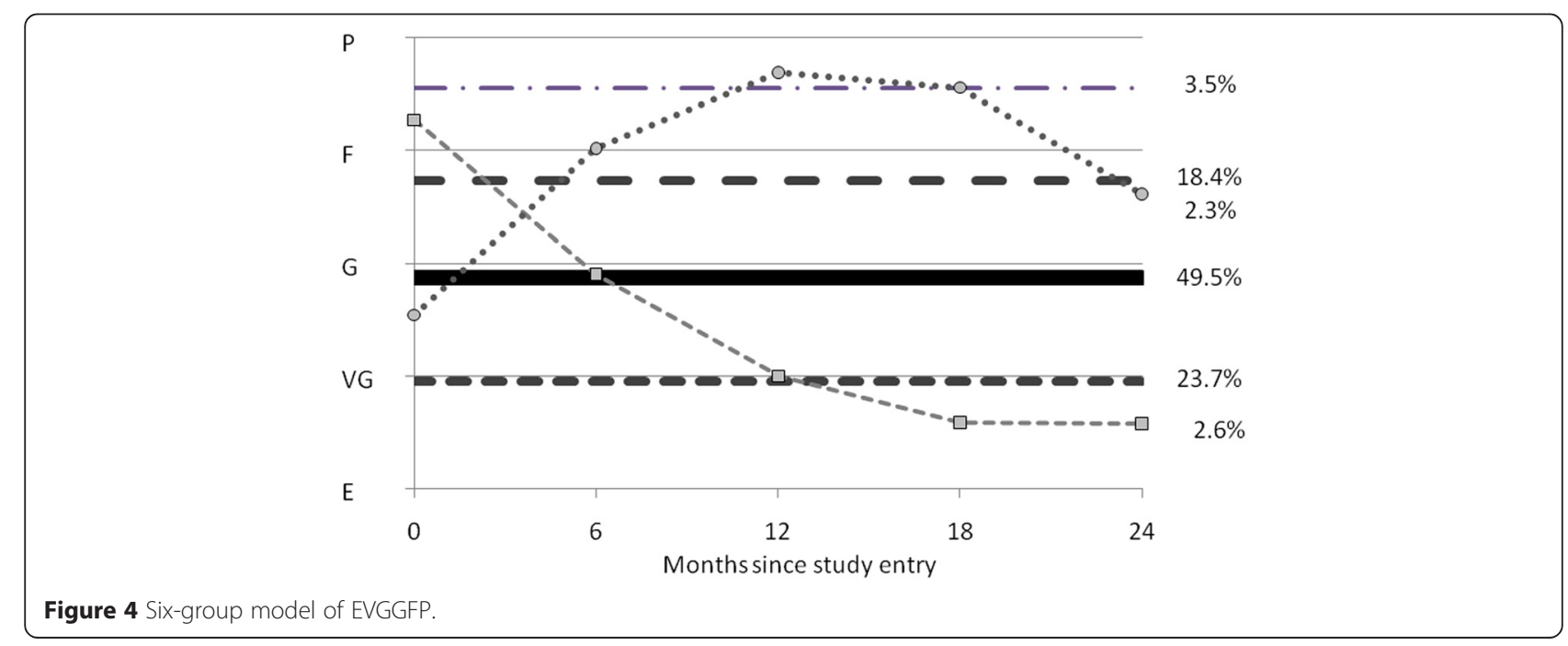




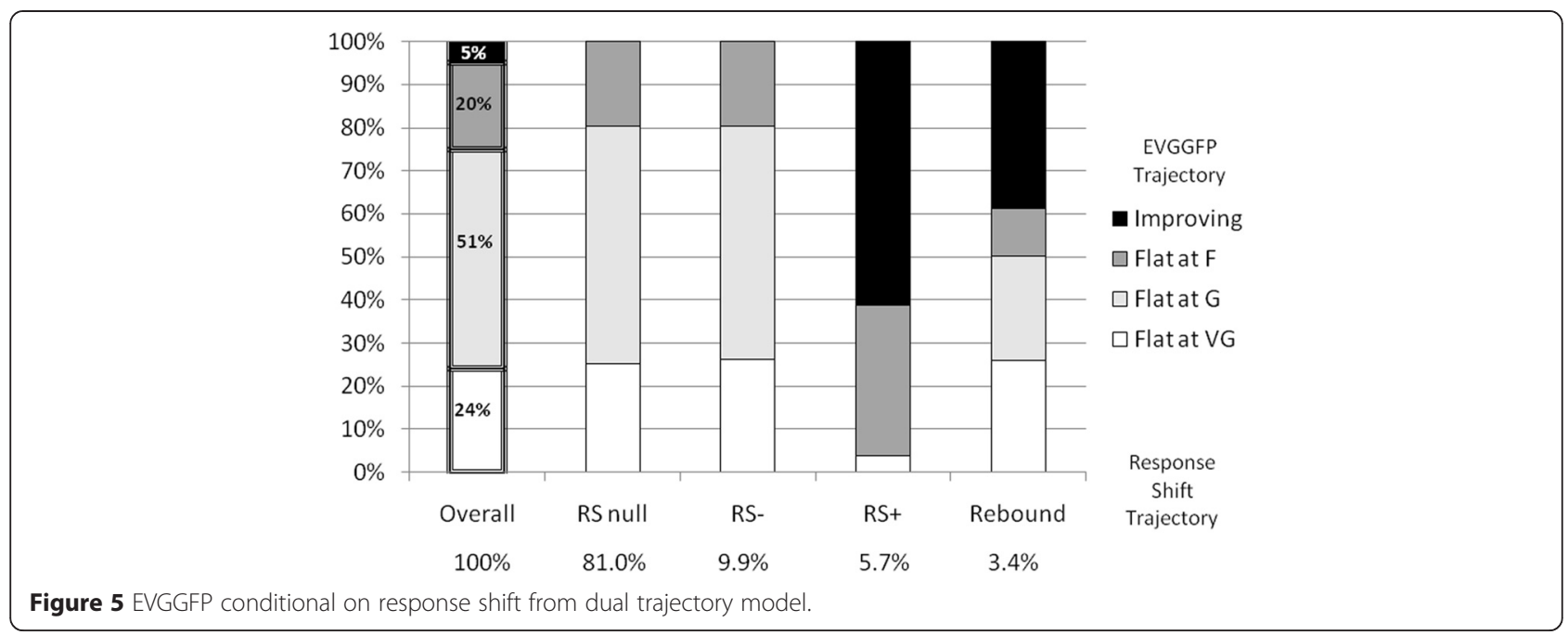

group with prevalent MS [15]. It was impossible to determine in that sample whether that was because no RS had occurred or whether it was just not detected because it had occurred prior to the measurement occasions, or even because of arbitrary measurement timing, chosen by the volunteer.
It is not possible, using this method, to identify which type of RS (reconceptualization, reprioritization, or recalibration) occurred and it would take qualitative work to untangle what drove the residual value. In our previous work [14], we found support for recalibration because of validation with the then-test.

Table 6 Baseline predictors of response shift

\begin{tabular}{|c|c|c|c|c|}
\hline & \multicolumn{2}{|c|}{ Negative $(n=31)$ v no RS $(n=294)$} & \multicolumn{2}{|c|}{ Positive $(n=23)$ v no RS $(n=294)$} \\
\hline & $\begin{array}{l}\text { Odds ratio } \\
(95 \% \mathrm{Cl})[\text { per unit } \\
\text { of predictor] }\end{array}$ & $\begin{array}{l}\text { Mean (RS-) versus mean } \\
\left(\mathrm{RS}_{0}\right) \text { (pooled SD) p-value } \\
\text { of the difference in means }\end{array}$ & $\begin{array}{l}\text { Odds ratio } \\
(95 \% \mathrm{Cl})[\mathrm{per} \\
\text { unit of predictor] }\end{array}$ & $\begin{array}{l}\text { Mean (RS-) versus mean } \\
\left(\mathrm{RS}_{0}\right) \text { (pooled } \mathrm{SD} \text { ) } \mathrm{p} \text {-value } \\
\text { of the difference in means }\end{array}$ \\
\hline $\begin{array}{l}\text { Age at diagnosis: older age at } \\
\text { diagnosis reduces the risk of RS+ }\end{array}$ & - & & $0.96(0.93,<1.00)$ & $30 \vee 38(14.8) p=0.0216$ \\
\hline $\begin{array}{l}\text { BSI Hostility: more hostility symptoms } \\
\text { (score } \geq 35 \text { ) at baseline increases } \\
\text { the risk of RS+ }\end{array}$ & & & $3.63(1.11,11.94)$ & $17 \%$ v $5 \%$ scored above $35 P=0.0477 \wedge$ \\
\hline \multicolumn{5}{|l|}{ SF-36 (OR based on a 10-pt difference) } \\
\hline GH: & - & & & \\
\hline \multirow{2}{*}{$\begin{array}{l}\text { Higher GH at baseline reduces } \\
\text { risk of RS+ }\end{array}$} & & & 0.74 & $41.6 \vee 55.5(21.5) p=0.0072$ \\
\hline & & & $(0.59,0.93)$ & \\
\hline \multicolumn{5}{|l|}{ Pain: } \\
\hline \multirow{2}{*}{$\begin{array}{l}\text { Lower pain at baseline reduces } \\
\text { risk for RS- and RS+ }\end{array}$} & 0.86 & $51.1 \vee 60.3(2.4)$ & 0.79 & $45.5 \vee 60.3(24.9) p=0.0080$ \\
\hline & $(0.74,1.01)$ & $p=0.0593$ & $(0.66,0.95)$ & \\
\hline $\mathrm{MH}:$ & - & & | & \\
\hline $\begin{array}{l}\text { Better } \mathrm{MH} \text { at baseline reduces } \\
\text { risk of RS+ }\end{array}$ & & & $0.76(0.60,0.95)$ & $59.6 \vee 68.7(17.3) p=0.0152$ \\
\hline \multicolumn{5}{|l|}{ Social: } \\
\hline \multirow{2}{*}{$\begin{array}{l}\text { Better social function at baseline } \\
\text { reduces the risk of RS- and RS+ }\end{array}$} & 0.88 & $58.9 \vee 69.3(27.7) p=0.0465$ & 0.87 & $57.6 \vee 69.3(27.9) p=0.0533$ \\
\hline & $(0.77,1.00)$ & & $(0.75,1.00)$ & \\
\hline RP: & - & & & \\
\hline $\begin{array}{l}\text { Better role physical at base-line } \\
\text { reduces the risk of RS+ }\end{array}$ & & & $0.87(0.76,<1.00)$ & $56.8 \vee 70.1(29.8) p=0.0398$ \\
\hline
\end{tabular}


RS was found to be associated with health perception. Several other predictors of RS were identified. Worse baseline pain and social function scores were found to be associated with the presence, but not direction, of RS: RS was more likely among those in either the positive or negative RS groups compared to those without RS. Those identified with positive response shift were also more likely to be younger, as well as having worse mental health, role physical functioning and general health perception scores and more hostility symptoms at baseline. These results are concordant with the finding from Lix et al. using discriminative analysis and logistic regression; this method identified pain and social function as predictors of reprioritization RS [39].

The EVGGFP question was selected as the outcome rather than the general health subscale for reasons of predictors to evaluate RS. While reports of symptoms, functioning, and perceived stress and social support may be good predictors for the rating of heath $[20,22,23]$, they would not be expected to predict some of the other constructs in the $\mathrm{GH}$ subscale such as the extent to which people expect their health to worsen.

Foundational work on the meaning of self-rated health $[36,37]$ indicates that people do not use the same frame of reference when answering the global health status item. Most commonly the rating is influenced by physical health including physical function and general physical condition; presence of positive health behaviours and absence of negative behaviours also play role as do health comparisons with social group. This early research has also shown that the frame of reference used did not depend on the person's rating of their health. In longitudinal studies, it would be relevant to ask whether the person's frame of reference changes over time, however, change in frame of reference is a mechanism of response shift [38]. Further research on the propensity for people to make a response shift is warranted.

A limitation of this analysis is that all predictors were obtained by self-report and could themselves have been influenced by RS. Although measured variables were included as part of the Cohort Study data collection, none were observed at all measurement occasions. While fixed predictors may increase the variation in the outcome explained by the predictive model, they do not contribute to the determination of RS as they do not contribute to discrepancies over time between observed and predicted scores.

This is not the first study to identify the presence of RS in individuals with IBD. Previous research to develop a new method of detecting reprioritization RS [39] also used data from the IBD Cohort Study, at the baseline and six month measurement occasions. RS was identified in some of the SF-36 subscales.
These results, combined with the current ones, suggest that some individuals with chronic conditions that are associated with exacerbations and remissions of symptoms over time are susceptible to RS. These flares in activity may serve as catalysts for RS [38]. However, even individuals not currently experiencing disease exacerbations have been shown to be susceptible to RS [40], perhaps because their expectations for high symptom burden were not realized.

In conclusion, the majority of people with IBD did not demonstrate a RS indicating that the health rating over time was stable in relation to that predicted by known time varying clinical variables. This adds to the evidence that the single question on self-rated health is useful for monitoring individuals over time [41].

\section{Competing interests}

The authors declare that they have no competing interests.

\section{Authors' contributions}

NEM - Developed the question and overall methodological approach; reviewed and interpreted the statistical analyses; edited the article. SCS - Participated in development of the question and methods used; conducted all statistical analyses; took the overall lead in drafting the manuscript; and addressing comments of co-authors. CNB - Principal investigator on the IBD cohort study; provided access to the data; interpretation of results and comments to manuscript. LML - Took the lead in the project that was funded to address response shift in multiple datasets; provided the link to the IBD dataset; consulted on the statistical methods and provided comments to the manuscript. All authors read and approved the final manuscript.

\section{Author details}

'Division of Clinical Epidemiology, Ross Pavilion R4. 29, Royal Victoria Hospital Site, McGill University Health Center, Montreal, QC H3A 1A1, Canada. ${ }^{2}$ Division of Clinical Epidemiology, Ross Pavilion R4. 36 Royal Victoria Hospital Site, McGill University Health Center, Montreal, QC H3A 1A1, Canada.

${ }^{3}$ University of Manitoba Inflammatory Bowel Disease Clinical and Research Centre, University of Manitoba, 804F-715 McDermot Ave, Winnipeg, MB R3E 3P4, Canada. ${ }^{4}$ University of Manitoba, S113-750 Bannatyne Ave, Winnipeg, MB R3E 0W3, Canada.

Received: 16 May 2014 Accepted: 6 March 2015 Published online: 06 May 2015

\section{References}

1. Berzon R, Hays RD, Shumaker SA. International use, application and performance of health-related quality of life instruments. Qual Life Res. 1993;2(6):367-8.

2. Revicki DA. Health-related quality of life in the evaluation of medical therapy for chronic illness. J Fam Pract. 1989;29(4):377-80.

3. Sprangers MA, Schwartz CE. Integrating response shift into health-related quality of life research: a theoretical model. Soc Sci Med. 1999;48(11):1507-15.

4. Schwartz CE, Sprangers MA. Reflections on genes and sustainable change: toward a trait and state conceptualization of response shift. J Clin Epidemiol. 2009;62:1118-23.

5. Schwartz CE, Ahmed S, Sawatzky R, Sajobi T, Mayo N, Finkelstein J, et al. Guidelines for secondary analysis in search of response shift. Qual Life Res. 2013;22(10):2663-73.

6. Schwartz CE, Bode R, Repucci N, Becker J, Sprangers MAG, Fayers PM. The clinical significance of adaptation to changing health: A meta-analysis of response shift. Qual Life Res. 2006;15:1533-50.

7. Nolte S, Elsworth G, Sinclair A, Osborne R. Tests of measurement invariance failed to support the application of the "then-test". J Clin Epidemiol. 2009;62:1173-80.

8. Brossart DF, Clay DL, Willson VL. Methodological and statistical considerations for threats to internal validity in pediatric outcome Data: Response Shift in Self-Report Outcomes. J Pediatr Psychol. 2002;27(1):97-107. 
9. Schmitt N, Pulakos E, Lieblein A. Comparison of three techniques to assess group-level beta and gamma change. Appl Psychol Meas. 1984;8:249-60.

10. Schmitt $N$. The use of analysis of covariance structures to assess beta and gamma change. Source. Multivariate Behavioral Research 1982. 1982;17(3):343-58.

11. Oort FJ, Visser MRM, Sprangers MAG. An application of structural equation modeling to detect response shifts and true change in quality of life data from cancer patients undergoing invasive surgery. Qual Life Res. 2005;14:599-609.

12. Oort FJ. Using structural equation modeling to detect response shifts and true change. Qual Life Res. 2005;14(3):587-98.

13. Barclay-Goddard R, Lix LM, Tate R, Weinberg L, Mayo NE. Response shift was identified over multiple occasions with a structural equation modeling framework. J Clin Epidemiol 2009.

14. Mayo NE, Scott SC, Dendukuri N, Ahmed S, Wood-Dauphinee S. Identifying response shift statistically at the individual level. Qual Life Res 2008.

15. Ahmed S, Mayo N, Scott S, Kuspinar A, Schwartz C. Using latent trajectory analysis of residuals to detect response shift in general health among patients with multiple sclerosis. [corrected]. Qual Life Res. 2011;20(10):1555-60.

16. Mayo NE, Nadeau L, Ahmed S, White C, Grad R, Huang A, et al. Bridging the gap: the effectiveness of teaming a stroke coordinator with patient's personal physician on the outcome of stroke. Age Ageing. 2007;37(1):32-8.

17. Mayo NE, Scott SC, Ahmed S. Case management poststroke did not induce response shift: the value of residuals. J Clin Epidemiol. 2009;62(11):1148-56.

18. Li Y, Rapkin B. Classification and regression tree uncovered hierarchy of psychosocial determinants underlying quality-of-life response shift in HIV/AIDS. J Clin Epidemiol. 2009;62(11):1138-47.

19. King-Kallimanis BL, Oort FJ, Visser MR, Sprangers MA. Structural equation modeling of health-related quality-of-life data illustrates the measurement and conceptual perspectives on response shift. J Clin Epidemiol. 2009;62(11):1157-64.

20. Graff LA, Walker JR, Clara I, Lix L, Miller N, Rogala L, et al. Stress, coping, distress and health perceptions in inflammatory bowel disease and community controls. Am J Gastroenterol. 2009;104:2959-69.

21. Graff LA, Walker JR, Lix L, Clara I, Rawsthorne P, Rogala L, et al. The relationship of inflammatory bowel disease type and activity to psychological functioning and quality of life. Clin Gerontol. 2012;4:1491-501.

22. Walker JR, Ediger JP, Graff LA, Greenfeld JM, Clara I, Lea L. The Manitoba IBD cohort study: a population-based study of the prevalence of lifetime and 12-month anxiety and mood disorders. Am J Gastroenterol. 2008;103:1989-97.

23. Lix LM, Graff LA, Walker JR, Clara I, Rawsthorne P, Rogala L, et al. Longitudinal study of quality of life and psychological functioning for active, fluctuating, and inactive disease patterns in inflammatory bowel disease. Inflamm Bowel Dis. 2008;14(11):1575-84.

24. Ware Jr JE, Kosinski M, Keller SD. SF-36 Physical \& Mental Scales: A User's Manual. Boston, Massachusetts: The Health Institute, New England Medical Center; 1994.

25. Ware JE, Keller SD. Interpreting general health measures. In: Spilker B, editor. Quality of Life and Pharmacoeconomics in Clinical Trials. 2nd ed. Philadelphia: Lippincott-Raven; 1996. p. 445-60.

26. Clara I, Lix LM, Walker JR, Graff LA, Miller N, Rogala L, et al. The Manitoba IBD Index: evidence for a new and simple indicator of IBD activity. Am J Gastroenterol. 2009:104:1754-63.

27. Guyatt GH, Mitchell A, Irvine EJ, Singer J, Williams N, Goodacre R, et al. A new measure of health status for clinical trials in inflammatory bowel disease. Gastroenterology. 1989;96:804-10.

28. Sainsbury A, Heatley RV. Review article: Psychosocial factors in the quality of life of patients with inflammatory bowel disease. Aliment Pharmacol Ther. 2005;21:499-508.

29. Cohen S, Kamarck T, Mermelstein R. A global measure of perceived stress. J Health Soc Behav. 1983:24:385-96.

30. Cohen S, Williamson GM. Perceived stress in a probability sample of the Unisted States. In: Spacapan SS, Oskemp S, editors. The social psychology of health. Sage; 1988:31-67.

31. Derogatis LR. Administratoin, scoring and procedures manual for the brief symptom inventory. 4th ed. Minneapolis, MN: National Computer Systems; 1993

32. Zimet GD, Dahlem NW, Zimet SG, Farley GK. The multidimensional scale of perceived social support. J Pers Assess. 1988;52:30-41.

33. Singer JD, Willett JB. Applied Longitudinal Data Analysis Modeling Change and Event Occurrence. New York: Oxford University Press; 2003.
34. Nagin DS. Group-Based Modeling of Development. Cambridge, Mass:: Harvard University Press; 2005.

35. Bollen KA, Barb KH. Pearson's R and Coarsely Categorized Measures. Am Sociol Rev. 1981:46:232-9.

36. Measuring Functioning and Well-Being: The Medical Outcomes Study Approach. Durham and London: Duke University Press; 1992.

37. Krause NM, Jay GM. What do global self-rated health items measure? Med Care. 1994;32(9):930-42.

38. Rapkin BD, Schwartz CE. Toward a theoretical model of quality-of-life appraisal: Implications of findings from studies of response shift. Health Qual Life Outcomes. 2004;2:14.

39. Lix LM, Sajobi TT, Sawatzky R, Liu J, Mayo NE, Huang Y, et al. Relative importance measures for reprioritization response shift. Qual Life Res. 2013;22(4):695-703.

40. King-Kallimanis BL, Oort FJ, Garst GJA. Using structural equation modelling to detect measurement bias and response shift in longitudinal data. Adv Stat Anal. 2010;94:139-56.

41. Rosenzveig A, Kuspinar A, Daskalopoulou SS, Mayo NE. Toward patientcentered care: a systematic review of how to ask questions that matter to patients. Medicine (Baltimore). 2014;93(22):e120.

\section{Submit your next manuscript to BioMed Central and take full advantage of:}

- Convenient online submission

- Thorough peer review

- No space constraints or color figure charges

- Immediate publication on acceptance

- Inclusion in PubMed, CAS, Scopus and Google Scholar

- Research which is freely available for redistribution

Submit your manuscript at www.biomedcentral.com/submit 